\title{
ESTIMATING THE COMPONENTS OF CONTINUOUS VARIATION
}

\author{
I. STATISTICAL \\ PATRICIA COOKE, R. MORLEY JONES and KENNETH MATHER \\ Agricultural Research Council Unit of Biometrical Genetics, \\ Department of Genetics, University of Birmingham \\ G. W. BONSALL \\ Rothamsted Experimental Station, Harpenden \\ and \\ J. A. NELDER \\ National Vegetable Research Station, Wellesbourne
}

\section{THE PROBLEM}

Received isiii.6r

THE genetical description and analysis of continuous variation depends, not on the isolation and measurement of the effects of single gene differences in the classical Mendelian fashion, but on the biometrical interpretation of the various statistics derivable from observation of related individuals in terms of parameters measuring the non-heritable and the different heritable components of variation. Two processes are therefore involved in such an analysis; first the description of the available statistics in terms of the genetical quantities, components of variation as they have been termed, of which use is to be made; and secondly the extraction of these quantities from the values observed for the statistics.

The genetical descriptions of the statistics obtained by observations of individuals standing in various degrees of relationship rests on the assumption that the heritable determinants of continuous variation are nuclear genes transmitted from parent to offspring on the chromosomes, segregating and recombining just as the genes of major effect. This assumption has been fully validated by experiment and descriptions have been formulated in terms of components representing the effects of additive gene action, dominance, interaction of non-allelic genes and genotype-environment interactions (Mather, 1949; Mather and Vines, 1952; Lerner, I950; Hayman and Mather, I955; Mather and Jones, I958; Kempthorne, I957; Falconer, 1960). The only remaining divergence is in respect of the notation for representing these components of variation and the composition of the various statistics in terms of them. The components are composite, each representing the summed effects of all the genes which can contribute to it, and are derived by theoretical consideration. In no case yet has the check been made of comparing the values of the components derived by biometrical analysis in the now familiar way with their values as expected from the measurement and summation of the effects of the individual genetic differences. Neither the desirability nor the difficulty of making such a check requires stressing. 
The estimation of the various components from constellations of observed statistics has been approached in several ways, of which the most generally applicable and useful is by a form of least squares analysis yielding estimates of the several components of variation. In its crudest form, as developed by Mather (1949), this consists of fitting constants for the various genetical components by minimising the sum of squares of the residuals of the several statistics, given equal weights. This process is simple but is open to several objections, especially that it takes regard, neither of the differences in precision with which the various statistics are observed experimentally, nor of the correlations that must exist between the values observed for them. Furthermore the standard errors which are obtained for the estimated values of the parameters are not fully reliable (Nelder, I953). Recently Nelder (1960) and Hayman (i 96o) have devised a method of estimation which does pay regard to both the differences in precision and the correlation of the statistics forming the raw materials of the analysis, and which leads to more reliable values for the standard errors as well as a more informative test of goodness of fit. Involving as it does the use of weights which depend on the values of the parameters themselves, this method necessarily requires iterative calculations which can make prohibitively heavy demands where only a desk calculator is available. The task is, however, well suited to the use of an electronic computer and it was decided to carry out an analysis in this way both for its intrinsic content and for the test it would afford of the reliability of the estimates arrived at by the earlier and simpler method of estimation. The statistical aspects of this estimation will be considered in this first paper and the genetical aspects in a second one.

\section{THE EXPERIMENT}

The experiment was based on two inbred lines of Drosophila melanogaster, Samarkand (S) and the Birmingham line of Oregon (B), the character used being the number of sternopleural chaetæ. In the experiment with which we are concerned, the lines were crossed reciprocally and $F_{2}$ 's were raised from the resulting $F_{1}$ 's. From these $\mathrm{F}_{2}$ 's, pair matings were made to the number of 346 from the cross $\mathrm{B} \times \mathrm{S}$ and ${ }_{3} 64$ from its reciprocal, $\mathrm{S} \times \mathrm{B}$. The resulting families are of the types which Mather (1949) has called BIPS.

An experiment of this magnitude must obviously be spread over time and the BIPS were raised in groups of up to 30 or 40 at a time. On each occasion that a group of BIPS was being raised, up to $3 \mathrm{~F}_{2}$ 's (in the case of $\mathrm{B} \times \mathrm{S}$ ) or 4 (in the case of $\mathrm{S} \times \mathrm{B}$ ) were also raised together with a single culture of each parental line and of each of the reciprocal $F_{1}$ 's. Parents, $F_{1}$ 's and $F_{2}$ 's were raised also at times when no BIPS were produced. The total numbers of cultures of P's, $F_{1}$ 's and $F_{2}$ 's appear in table $I$. The chaetæ were counted on Io females and Io males from each culture in these generations and also in the 
BIPS. Conditions were held as constant as possible over the period of the experiment and an analysis of variance of the $\mathrm{F}_{2}$ results showed that the mean number of chaetæ did not vary significantly more between cultures raised on different occasions, than between cultures

TABLE

Total numbers of cultures scored, and numbers on each occasion

\begin{tabular}{|c|c|c|c|c|c|c|c|c|}
\hline \multirow{2}{*}{ Generation } & \multicolumn{2}{|c|}{ Parents } & \multicolumn{2}{|c|}{$F_{1}$ 's } & \multicolumn{2}{|c|}{$F_{2}{ }^{\prime} s$} & \multicolumn{2}{|c|}{ BIPS } \\
\hline & B & $\mathrm{S}$ & $\overparen{B \times S}$ & $\mathbf{S} \times \mathbf{B}$ & $\mathrm{B} \times \mathrm{S}$ & $\mathbf{S} \times \mathbf{B}$ & $\overparen{B \times S}$ & $\mathbf{S} \times \mathbf{B}$ \\
\hline Total No. & & 29 & 29 & 29 & 44 & 49 & 346 & 364 \\
\hline Per occasion & 1 & I & 1 & 1 & $1-3$ & $1-4$ & I-30 & I-37 \\
\hline
\end{tabular}

raised at the same time. A similar test was not possible with the results from the parents and $F_{1}$ 's, but no trend of the means could be observed graphically with time in these. There is thus no evidence that the spread of the experiment over time introduced any additional

TABLE 2

Mean and variance of parents, $F_{1}$ 's and $F_{2}$ 's

\begin{tabular}{|c|c|c|c|c|c|c|}
\hline & $\begin{array}{l}\text { No. of } \\
\text { cultures }\end{array}$ & Mean & $\begin{array}{c}\text { Mean variance } \\
\text { within } \\
\text { cultures }\end{array}$ & d.f. & $\begin{array}{l}\text { Variance of } \\
\text { mean of } 10 \\
\text { over occasions }\end{array}$ & d.f. \\
\hline $\begin{array}{c}\text { Parents } \\
\text { B } \\
\end{array}$ & 29 & $\begin{array}{l}22 \cdot 4724 \\
22.9310\end{array}$ & $\begin{array}{l}3 \cdot 1376 \\
2 \cdot 9628\end{array}$ & $\begin{array}{l}26 \mathrm{I} \\
26 \mathrm{I}\end{array}$ & $\begin{array}{l}0.6940 \\
0.5182\end{array}$ & $\begin{array}{l}28 \\
28\end{array}$ \\
\hline $\begin{array}{l}0 \\
0 \\
+\end{array}$ & 29 & $\begin{array}{l}18.2034 \\
18.5207\end{array}$ & $\begin{array}{l}1 \cdot 8333 \\
1 \cdot 9374\end{array}$ & $\begin{array}{l}261 \\
261\end{array}$ & $\begin{array}{l}0 \cdot 4196 \\
0 \cdot 23^{8} 5\end{array}$ & $\begin{array}{l}28 \\
28\end{array}$ \\
\hline${ }^{F_{1}} \mathrm{~B} \times \mathrm{S} \underset{\substack{q\\
}}{ }$ & 29 & $\begin{array}{l}19 \cdot 5^{828} \\
20 \cdot 45^{86}\end{array}$ & $\begin{array}{l}2 \cdot 2331 \\
2 \cdot 0184\end{array}$ & $\begin{array}{l}261 \\
261\end{array}$ & $\begin{array}{l}0.3272 \\
0.3354\end{array}$ & $\begin{array}{l}28 \\
28\end{array}$ \\
\hline $\mathrm{S} \times \mathrm{B} \underset{q}{q}$ & 29 & $\begin{array}{l}20 \cdot 1172 \\
20 \cdot 3138\end{array}$ & $\begin{array}{l}2 \cdot 6927 \\
\mathrm{I} \cdot 8372\end{array}$ & $\begin{array}{l}26 \mathrm{I} \\
26 \mathrm{I}\end{array}$ & $\begin{array}{l}0 \cdot 2419 \\
0 \cdot 4618\end{array}$ & $\begin{array}{l}28 \\
28\end{array}$ \\
\hline 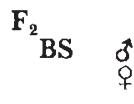 & 33 & $\begin{array}{l}19 \cdot 7091 \\
20 \cdot 1205\end{array}$ & $\begin{array}{l}4 \cdot 8660 \\
3 \cdot 1475\end{array}$ & $\begin{array}{l}297 \\
297\end{array}$ & $\begin{array}{l}0.5033 \\
0.4139\end{array}$ & $\begin{array}{l}32 \\
32\end{array}$ \\
\hline \begin{tabular}{ll} 
SB & \multirow{2}{*}{} \\
\multirow{2}{*}{}
\end{tabular} & 37 & $\begin{array}{l}19 \cdot 8224 \\
20 \cdot 459^{2}\end{array}$ & $\begin{array}{l}4 \cdot 4303 \\
4 \cdot 1654\end{array}$ & $\begin{array}{l}333 \\
333\end{array}$ & $\begin{array}{l}0.5223 \\
0.5725\end{array}$ & $\begin{array}{l}36 \\
3^{6}\end{array}$ \\
\hline
\end{tabular}

source of variation. The distinction between occasions has therefore been omitted from account in the analysis of the results.

The overall mean numbers of chaetæ and variances, both of individuals within cultures and of means between cultures, are given for P's $F_{1}$ 's and $F_{2}$ 's in table 2, together with the numbers of degrees 
of freedom on which the variances are based. The variances of parents and $F_{1}$ 's must obviously be non-heritable and provide the direct estimates of the non-heritable components of variation $E_{1}$ (of individuals within cultures) and $\mathrm{E}_{2}$ (of means between cultures) used in the analysis. It will be seen that males always showed lower means and generally showed higher variances than did their sisters. The $B$ parent also showed higher variances than $S$ and the $F_{1}$ 's which, however, did not differ markedly or consistently among themselves. This difference in variances was accommodated by estimating $E_{1}$ and $E_{2}$ as the sum of one quarter of the variance of each parental line and one half of the variance of the corresponding $F_{1}$.

Strictly the BIPS should be raised by random pair matings among $\mathrm{F}_{2}$ flies and this course was followed at first. For some reason, however, a correlation appeared between the chaeta counts of the male and

TABLE 3

Frequency distribution of $F_{2}$

\begin{tabular}{|c|c|c|c|c|c|c|c|c|c|c|c|c|c|c|c|c|}
\hline \multicolumn{4}{|c|}{ Cross } & 15 & 16 & 17 & 18 & 19 & 20 & 21 & 22 & 23 & 24 & 25 & 26 & Total \\
\hline BS & $\begin{array}{l}0 \\
\vdots \\
\vdots\end{array}$ & . & . & $\begin{array}{l}1 \\
\ldots\end{array}$ & $\begin{array}{l}5 \\
I\end{array}$ & $\begin{array}{l}9 \\
7\end{array}$ & $\begin{array}{l}12 \\
14\end{array}$ & $\begin{array}{r}19 \\
16\end{array}$ & $\begin{array}{l}21 \\
2 \pi\end{array}$ & $\begin{array}{l}14 \\
18\end{array}$ & $\begin{array}{r}8 \\
85\end{array}$ & $\begin{array}{l}7 \\
6\end{array}$ & $\begin{array}{l}2 \\
2\end{array}$ & $\begin{array}{l}\boldsymbol{I} \\
\ldots\end{array}$ & $\begin{array}{c}I \\
\ldots\end{array}$ & $\begin{array}{l}100 \\
100\end{array}$ \\
\hline SB & $\begin{array}{l}0 \\
q\end{array}$ & . & . & 1 & $\begin{array}{l}4 \\
1\end{array}$ & $\begin{array}{l}8 \\
1\end{array}$ & $\begin{array}{r}13 \\
7\end{array}$ & $\begin{array}{l}21 \\
16\end{array}$ & $\begin{array}{l}15 \\
20\end{array}$ & $\begin{array}{l}13 \\
22\end{array}$ & $\begin{array}{l}14 \\
11\end{array}$ & $\begin{array}{r}7 \\
12\end{array}$ & $\begin{array}{l}3 \\
4\end{array}$ & $\dddot{4}$ & $\begin{array}{c}I \\
\ldots\end{array}$ & $\begin{array}{l}100 \\
100\end{array}$ \\
\hline
\end{tabular}

female parents taken. It was therefore decided deliberately to make up matings with frequencies corresponding approximately to those expected by combinations of the frequencies with which males and females were observed to fall in the various chaeta classes of the $F_{2}$ 's. The frequency distributions of chaeta number in 100 flies of each of the $F_{2}$ 's are shown in table 3 and the distribution of the matings used to raise BIP families in table 4 .

The chaeta frequency distributions used in determining the mating frequencies were taken from io of the early $F_{2}$ families. The counts from these cultures are excluded from the calculations of the variances of individuals within $F_{2}$ cultures $\left(V_{1 F 2}\right)$ used in both the analyses to be described and also from the variances between $F_{2}$ cultures used only in the second analysis. In addition one $F_{2}$ culture from $B \times S$ and two from $\mathrm{S} \times \mathrm{B}$ were omitted as the incubator temperature fluctuated unduly during the time they were being raised.

The BIPS yield, of course, values for overall mean number of chaetæ and also variances within $\left(\mathrm{V}_{2 \mathrm{S3}}\right)$ and between $\left(\mathrm{V}_{1 \mathrm{S3}}\right)$ cultures, as well as the covariance of BIP means with the parental averages $\left(\mathrm{W}_{1 \mathrm{1S23}}\right)$. The notation is that of Mather and Vines (1952). Scaling tests using parental $F_{1}, F_{2}$ and BIP means were carried out on males and females separately by the method of Cavalli (1952). These 
indicated the presence of interaction in females $\left(\chi_{[2]}^{2}=25.27\right)$ and even more strongly in the males $\left(\chi_{[2]}^{2}=48.57\right)$. As will be seen in the later paper these interactions were neither very large as compared

TABLE 4

Chaeta number in the $F_{2}$ parents of BIP families

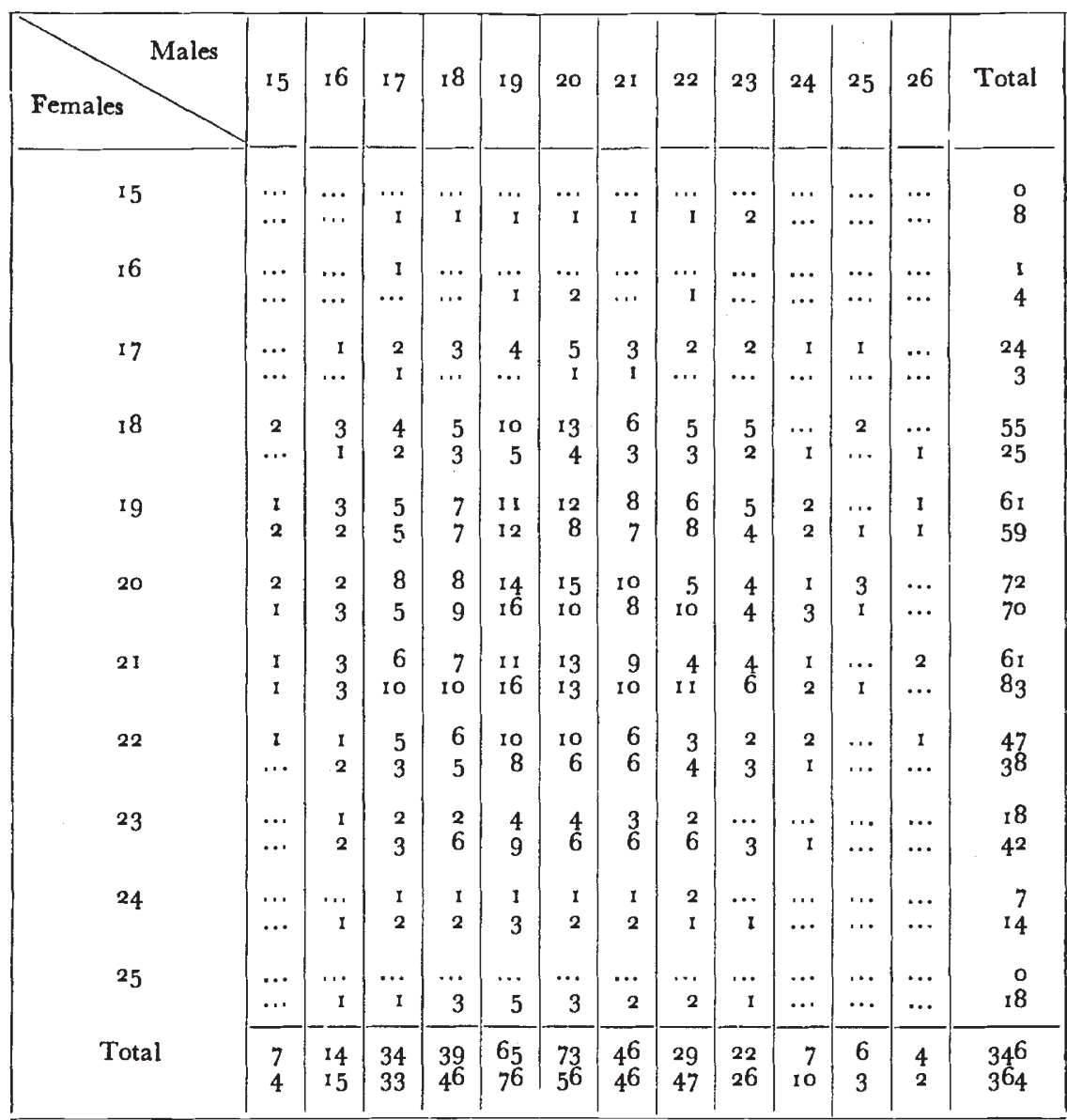

The figures in the body of the table are the numbers of matings with male parent having the chaeta number as at the head of the column and female parent the chaeta number as in the left margin. The upper figure in each cell is the number of matings from the $F_{2}$ of $B \times S$, and the lower figure that from the $F_{2}$ of $S \times B$.

with the main components of variation nor of a kind that could easily be scaled out, and so no rescaling was in fact attempted.

The statistics available for estimating the components of variation are collected together in table 5. They are given for sexes and reciprocal crosses separately, and for the whole experiment.

The figures are as consistent as could be expected except for the females of $\mathrm{B} \times \mathrm{S}$. These give a very high value for $\mathrm{W}_{1 \mathrm{~s} 23}$ accompanied by low values for $V_{1 F 2}$ and $V_{253}$. Furthermore, the values for the 
$\mathrm{B} \times \mathrm{S}$ females are not merely inconsistent with those for the other three parts of the experiment, they are inconsistent with one another. Thus $\mathrm{W}_{1 \mathrm{s23}}$, whose expectation is $\frac{1}{4} \mathrm{D}$, falls short of that of $\mathrm{V}_{1 \mathrm{~s} 3}$, whose expectation is $\frac{1}{4} \mathrm{D}+\frac{1}{16} \mathrm{H}+\mathrm{E}_{2}$, by only 0.1377 , a value which is less than one third the direct estimate of $E_{2}$. Again $W_{1 s_{23}}$ is only $1 \cdot 8289$ less than $V_{2 s 3}$ whose expectation includes $E_{1}$, of which the direct estimate is $2 \cdot 4906$. This set of results must therefore be regarded as

TABLE 5

Statistics used in estimation of the components of variation and, in brackets, the degrees of freedom on which they are based. The expectation in terms of the components of variation is given for each statistic

\begin{tabular}{|c|c|c|c|c|c|}
\hline Statistics & BS $\pi$ & BS +9 & $\mathrm{SB} \sigma^{*}$ & SB $q$ & $\begin{array}{l}\text { Overall } \\
\text { Average }\end{array}$ \\
\hline $\mathrm{V}_{\frac{1 F_{2}}{2} D+1} \dot{H}+E_{1}$ & $\begin{array}{r}4 \cdot 8660 \\
(297)\end{array}$ & $\begin{array}{r}3 \cdot 1475 \\
(297)\end{array}$ & $\begin{array}{r}4.4303 \\
(333)\end{array}$ & $\begin{array}{r}4 \cdot 1654 \\
(333)\end{array}$ & $4 \cdot 1606$ \\
\hline $\mathrm{V}_{\frac{1}{4} \mathrm{~S}_{3}}{ }_{{ }_{11}^{1} \mathrm{H}} \dot{\mathrm{H}}+\mathrm{E}_{3}$ & $\begin{array}{r}\mathrm{I} \cdot 0673 \\
(345)\end{array}$ & $\begin{array}{r}\mathrm{I} \cdot 19^{2} \mathrm{I} \\
(345)\end{array}$ & $\begin{array}{r}\mathrm{I} \cdot 2002 \\
(363)\end{array}$ & $\begin{array}{r}\mathrm{I} \cdot 1960 \\
(363)\end{array}$ & $1 \cdot 1648$ \\
\hline$\underset{\substack{1 \mathrm{~S}_{23} \\
\mathrm{t} D}}{\mathrm{D}_{\mathrm{D}}}$ & $\begin{array}{r}0.5797 \\
(345)\end{array}$ & $\begin{array}{r}1 \cdot 0544 \\
(345)\end{array}$ & $\begin{array}{c}0.5376 \\
(363)\end{array}$ & $\begin{array}{r}0.7318 \\
(363)\end{array}$ & 0.7236 \\
\hline 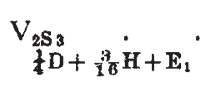 & $\begin{array}{l}3.2767 \\
(3114)\end{array}$ & $\begin{array}{l}2 \cdot 8733 \\
(3 \mathrm{I} 14)\end{array}$ & $\begin{array}{l}3 \cdot 3076 \\
(3276)\end{array}$ & $\begin{array}{l}3.1315 \\
(3276)\end{array}$ & $3 \cdot 1491$ \\
\hline$E_{1}$. & $\begin{array}{r}2 \cdot 6854 \\
(522)\end{array}$ & $\begin{array}{r}2 \cdot 4906 \\
(522)\end{array}$ & $\begin{array}{r}2 \cdot 2630 \\
(522)\end{array}$ & $\begin{array}{r}1.8873 \\
(522)\end{array}$ & $2 \cdot 33^{16}$ \\
\hline $\mathrm{E}_{2}$ & $\begin{array}{r}0.488 \mathrm{I} \\
\left(5^{6}\right)\end{array}$ & $\begin{array}{r}0.4268 \\
(56)\end{array}$ & $\begin{array}{r}0.3308 \\
(56)\end{array}$ & $\begin{array}{r}0.3502 \\
(56)\end{array}$ & 0.3990 \\
\hline
\end{tabular}

suspect on genetical grounds. The other three sets of results are not open to any such suspicion. The consequences of these inconsistencies, for which no reason can be advanced, will be seen in the results of the analysis.

\section{THE UNWEIGHTED ANALYSIS}

The analysis by the crude unweighted procedure follows the same pattern as the example described by Mather (1949, pages 66-68 and 95-96) and his matrices were used in the calculations. It should be observed that this analysis is strictly valid only where all the genetic differences follow an autosomal pattern of inheritance, whereas in fact, the sex chromosomes must be expected to contribute to the differences between $\mathrm{B}$ and $\mathrm{S}$. If we neglect any possible effect of the $\mathrm{Y}$ chromosome, the males cannot be heterozygous for any differences, so that in segregating generations they will contribute less to $\mathrm{H}$ and more to $\mathrm{D}$ than the assumption of autosomal inheritance allows. The females of a family receive one common $\mathrm{X}$ from their fathers and so will always give backcross ratios for any segregating gene. They will 
therefore, on the average contribute less to $\mathrm{D}$ and more to $\mathrm{H}$ than the autosomal formula allows. There is thus some tendency towards compensation between the sexes and in any case, as will be seen from the later paper, the contribution of the $\mathrm{X}$ chromosome to the parental difference, taken as a unit, was not large. The use of autosomal formulæ should not therefore lead to any major disturbances in the estimates of the components of variation and indeed the difficulty it introduces must be considerably less than that springing from the unexplained inconsistencies of the statistics noted above.

Since the available statistics include $V_{2 s 3}$, a test for the effects of recoverable linkage on the variation is possible as this statistic is of the second rank in relation to recombination, whereas $V_{1 F 2}, V_{153}$

TABLE 6

Analyses of variance for linkage. The entries are mean squares

\begin{tabular}{|c|c|c|c|c|}
\hline Data & $\underset{1 \mathrm{df}}{\text { Linkage }}$ & $\begin{array}{l}\text { Remainder } \\
\text { I df }\end{array}$ & VR & $\begin{array}{c}\mathbf{P} \\
\text { (per cent.) }\end{array}$ \\
\hline $\begin{array}{ll}\text { BS } 0 \\
\text { BS } \\
\text { SB } \\
\text { SB } \\
\text { SB }\end{array}$ & $\begin{array}{l}0.3861 \\
0.0949 \\
0.0510 \\
0.0057\end{array}$ & $\begin{array}{l}0.0275 \\
0.0023 \\
0.0015 \\
0.0034\end{array}$ & $\begin{array}{r}14 \cdot 0400 \\
4 \mathrm{I} \cdot 2609 \\
34 \cdot 0000 \\
\mathrm{I} \cdot 6765\end{array}$ & $\begin{array}{l}\ldots \\
10-5 \\
\cdots \\
\cdots\end{array}$ \\
\hline Overall. & 0.0204 & 0.0012 & $17 \cdot 0000$ & $\ldots$ \\
\hline
\end{tabular}

and $W_{1 \mathrm{~S} 23}$ are of the first rank (Mather, 1949; Mather and Vines, I952 . If, therefore, recombination is materially affecting the components of variation the $\mathrm{D}$ and $\mathrm{H}$ of $\mathrm{V}_{2 \mathrm{~s} 3}$ will not be the same as the $\mathrm{D}$ and $\mathrm{H}$ of the other statistics. Two analyses are therefore conducted, the inclusive which brings in $\mathrm{V}_{2 \mathrm{~S} 3}$ and the exclusive which omits it, so that in effect it becomes its own expectation and thus accommodates any change in the values of $\mathrm{D}$ and $\mathrm{H}$. The comparison of the expectations, found from inclusive and exclusive estimates of the components, with the values observed for the statistics, allows an analysis of variance to be carried out in which a mean square for linkage is compared with a mean square for residual variation.

Since six statistics are available and four components of variation are estimated in the inclusive analysis, two degrees of freedom remain for assessing the variation arising from differences between observation and inclusive expectation. The exclusive analysis in effect estimates five parameters, leaving one degree of freedom for residual variation. The difference between these two mean squares springs from linkage effects (or from interactions indistinguishable from them-see Opsahl (1956)), so that the linkage item in the analysis of variance takes one degree of freedom, the residual variation in the analysis being the residual variation of the exclusive calculations. The analyses of variance are set out in table 6 , for the males and 
females of the two reciprocals separately and for the combined data. There is a suggestion of linkage effects in the $\mathrm{B} \times \mathrm{S}$ females, whose results however we have judged to be suspect on other grounds. The overall results give no significant indication of linkage effects. However, if we pool over the individual observations we can obtain a variance ratio of 15.50 for four and four degrees of freedom which has a $\mathrm{P} \bumpeq 0 \cdot 0 \mathrm{I}$. This would seem to imply some degree of heterogeneity in respect of linkage between the four parts of the experiment. There is therefore no good evidence of consistent disturbances due to linkage and we have taken the inclusive estimates of the components, obtained ignoring linkage effects, for further consideration.

The estimates are set out in table 7. Two points require comment. The standard errors shown in the body of the table are derived from

TABLE 7

Estimates of the components of crosses from the unweighted inclusive analysis

\begin{tabular}{|c|c|c|c|c|c|c|}
\hline & BS $\sigma$ & BS $q$ & $\mathrm{SB}$ む & SB ? & $\begin{array}{l}\text { Overall } \\
\text { average }\end{array}$ & $\begin{array}{l}\text { Pooled } \\
\text { s.e. }\end{array}$ \\
\hline $\begin{array}{l}\mathrm{D} \\
\mathrm{H} \\
\mathrm{E}_{1} \\
\mathrm{E}_{2}\end{array}$ & $\begin{array}{l}2 \cdot 8813 \pm 1 \cdot 6010 \\
1 \cdot 8795 \pm 3 \cdot 957 \mathrm{I} \\
2 \cdot 4616 \pm 0 \cdot 4417 \\
0.3588 \pm 0.3455\end{array}$ & $\begin{array}{r}3.8534 \pm 0.7761 \\
-4.5432 \pm 1.9184 \\
2.5363 \pm 0.2142 \\
0.4698 \pm 0.1676\end{array}$ & $\begin{array}{l}2.5123 \pm 0.5704 \\
3.3469 \pm 1 \cdot 4111 \\
2 \cdot 2175 \pm 0.1575 \\
0.3469 \pm 0.1233\end{array}$ & $\begin{array}{l}2.9550 \pm 0.2387 \\
3.0118 \pm 0.5902 \\
1.8834 \pm 0.0656 \\
0.3096 \pm 0.0520\end{array}$ & $\begin{array}{l}3.0480 \pm 0.3659 \\
0.9550 \pm 0.9043 \\
2.3125 \pm 0.1010 \\
0.3711 \pm 0.0787\end{array}$ & $\begin{array}{l} \pm 0.9420 \\
\pm 2.3284 \\
\pm 0.2600 \\
\pm 0.2032\end{array}$ \\
\hline
\end{tabular}

The standard errors derived from the error variances in the unweighted analyses are shown by each statistic, and those for the pooled estimates of error are given in the right-most column (see in text).

the differences between the values observed for the six statistics and the values expected using the inclusive estimates of the four components of variation. The residual variation, and by derivation the standard errors of the components, are assessed from two degrees of freedom in each of the four parts of the experiment as noted above. The standard errors should therefore be used with corresponding caution. Since, however, the four parts of the experiment may be regarded as affording independent values of the six statistics and independent estimates of the four components their sum of squares for residual variation may be pooled to yield a combined estimate of residual variation based of course on $2 \times 4=8$ degrees of freedom. Common standard errors, applying to the estimated components from all four parts of the experiment have been calculated from this combined residual mean square and are shown at the end of the table. The overall estimates of each component is virtually the mean of the four estimates for the four parts of the experiment and so will take therefore a standard error half that of the common standard error applying to each of the four individual estimates.

The second point requiring comment is the difference between the components as estimated from the $\mathrm{B} \times \mathrm{S}$ females as compared with 
their brothers and the two sexes from $S \times B$. As would be expected from the high covariance and the low variances $B \times S$ females yielded as compared with the rest of the experiment, they give a high value for $\mathrm{D}$ while $\mathrm{H}$ appears negative and this negative value approaches significance $\left(t_{[2]}=2 \cdot 3683\right.$ and $\mathrm{P}=0.2-0 \cdot \mathrm{I}$ using the individual estimate of its standard error, and $t_{[8]}=\mathrm{I} \cdot 95^{12}$ and $\mathrm{P}=0 . \mathrm{I}-0.05$ using the common standard error based on the pooled residual variation). The estimates from the $\mathrm{S} \times \mathrm{B}$ females and the two groups of males are both reasonable and consistent among themselves. Even the difference of $\mathrm{H}$ from the $\mathrm{B} \times \mathrm{S}$ males $(\mathrm{I} \cdot 88)$ on the one hand and the average $\mathrm{H}$ of the sexes from $\mathrm{S} \times \mathrm{B}(3 \cdot 18)$ is not significant. Our view that the $\mathbf{B} \times \mathbf{S}$ females are aberrant in the data they yielded is thus further strenthened.

\section{WEIGHTED ANALYSIS}

The unweighted analysis is simple to use in that the matrices it involves may be inverted once and for all (Mather, 1949), but it takes no account either of the differences in precision with which the various statistics are found experimentally or of the correlations which must exist between the values observed for them.

It may be expected to extract the greater part of the information from the data, but in so far as there is any loss of efficiency, the final test of goodness of fit between observation and expectation must be, to that extent, suspect. Furthermore, the standard errors it yields for the estimates of the components of variation will be unreliable, partly because of this loss of efficiency and partly because any positive correlations among the initial statistics will tend to cause them to be underestimated. Unbiased estimates of the standard errors applicable to estimates obtained by unweighted analysis could be found empirically where the experiment is replicated, by obtaining separate estimates of $\mathrm{D}, \mathrm{H}$ and $\mathrm{E}$ from each section of the experiment and deriving the standard errors of the components from the variation between these replicated estimates (Nelder, 1953). The numbers of degrees of freedom available for finding these empirical standard errors must, however, be small unless the sub-division of the experiment is extreme.

An analysis in which the statistics are weighted to take account of their precisions and their correlations, will overcome these difficulties and Nelder (1960) and Hayman (1960) have independently shown how the weights may be derived and the analysis carried out. Full accounts of the method will be found in these papers.

In the unweighted analysis certain genetic sampling terms which depend on the size of family, plot or culture, as the case may be, and enter into the expectations of statistics such as the variance of BIP means, are neglected. In the weighted analysis no further complication arises from the inclusion of these terms and also of the variance of $F_{2}$ culture means as an additional statistic. The comparison 
between weighted and unweighted analysis is thus slightly complicated, but in the experiments reported here much the greater part of the difference in precision is due to the weighting itself rather than to these other refinements.

For most purposes it is sufficient to calculate the weights and correlations from a model which assumes that the character under consideration is normally distributed in the various families, and that the correlations are normal. For example, if $v_{0}=\mathrm{V}_{1 \mathrm{~F} 2}, v_{1}=\mathrm{V}_{1 \mathrm{~s} 3}$, $w=\mathrm{W}_{1 \mathrm{~s} 23}$, based on $\mathrm{N}$ degrees of freedom and $v_{2}=\mathrm{V}_{2 \mathrm{~s} 3}$ based on $\mathrm{N}^{\prime}$ degrees of freedom and $\mathrm{V}_{0}, \mathrm{~V}_{1}, \mathrm{~W}$ and $\mathrm{V}_{2}$ denote the corresponding expectations, this gives for the sampling variance matrix of the observed variances and covariances $\left(v_{0}, v_{1}, \omega\right.$ and $\left.v_{2}\right)$

$$
\left[\begin{array}{llll}
2 \mathrm{~V}_{0}^{2} / \mathrm{N} & 2 \mathrm{~W}^{2} / \mathrm{N} & 2 \mathrm{~V}_{0} \mathrm{~W} / \mathrm{N} & 0 \\
2 \mathrm{~W}^{2} / \mathrm{N} & 2 \mathrm{~V}_{1}^{2} / \mathrm{N} & 2 \mathrm{~V}_{1} \mathrm{~W} / \mathrm{N} & 0 \\
2 \mathrm{~V}_{0} \mathrm{~W} / \mathrm{N} & 2 \mathrm{~V}_{1} \mathrm{~W} / \mathrm{N} & \left(\mathrm{W}^{2}+\mathrm{V}_{0} \mathrm{~V}_{1}\right) / \mathrm{N} & 0 \\
0 & 0 & 0 & \mathrm{~V}_{2}^{2} / \mathrm{N}^{\prime}
\end{array}\right]
$$

Nelder (1960) has considered, in certain cases, how far this approximate variance matrix represents the true sampling variances and covariances of the observed statistics and has found it satisfactory, at least when the number of genes is not too small. However, $V_{0}, V_{1}$, $\mathrm{W}$ and $\mathrm{V}_{2}$ are not known in advance, but have to be estimated from the analysis. An iterative process is therefore necessary starting with the empirical values $v_{0}, v_{1}, w$ and $v_{2}$. Such a process has been carried out by Hayman ( 1960 ) but is clearly a very heavy operation unless an electronic computer is available.

The non-random choice of matings among the $\mathrm{F}_{2}$ 's in the Drosophila experiment must presumably have reduced the variance of $\mathrm{W}_{1 \mathrm{~s} 23}$ and also the effective number of degrees of freedom in $V_{1 s 3}$, but it was not practicable to correct for this in the weighted analysis. The fact that, as we shall see, the total residual $\chi^{2}$ was $7 \cdot 449$ with 8 d.f. suggests that the weights were not seriously wrong.

The iterative weighted least squares procedure has now been programmed for the Elliott 4 or computer at Rothamsted. The programme is sufficiently general to deal with most, if not all, cases which are likely to arise in practice. For example, the statistics may fall into groups such that any pair belonging to the same group are correlated, but statistics in different groups are uncorrelated. This is the most frequent situation, a group of statistics consisting of the variances of a set of variables and all possible correlations between pairs of these variables. The details of the procedure are as set out in Nelder ( 1960 ) except that the rules for forming the variance matrix of the statistics have been generalised, but the correction for kurtosis has not been included.

The computer is able to handle a number of observed variances and covariances considered as a $n \times \mathrm{r}$ column vector $\mathbf{x}$, and a number 
of estimated parameters considered as a $m \times 1$ column vector $\boldsymbol{\theta}$ where $n \leqq 16, m \leqq 10$ and $n m \leqq 128$. The greater part of the calculation consists of standard operations on matrices. The only special feature of the programme is the method used in providing all the information required for the calculation of the variance matrix $\mathbf{V}$ of $\mathbf{x}$.

Suppose there are $s$ associated sets of variances and covariances, the $t$ th set having $v_{t}$ variances, $c_{t}$ covariances and $N_{t}$ degrees of freedom. Form a symmetric matrix $\mathrm{Z}$ by placing all the variances in the diagonal positions and each covariance in the same row and column as its associated variances. Let $x_{i}$, the $i$ th element of the observation vector $\mathbf{x}$, be in the $r_{i}$ th row and the $c_{i}$ th column above the diagonal of the $\mathrm{Z}$ matrix.

Then

$$
\operatorname{cov}\left(x_{i}, x_{j}\right)=\left(\mathrm{X}_{r_{i} r_{j}} \mathrm{X}_{c_{i j}^{c}}+\mathrm{X}_{r_{i j} c_{j}} \mathrm{X}_{r_{j} c}\right) / \mathrm{N}_{i}
$$

where $\mathrm{X}_{k}$ is the expected value of $x_{k}$ as estimated from the previous cycle of the iteration. In the first cycle $\mathrm{X}_{k}=x_{k}$.

In order to economise in storage space, the $\mathrm{Z}$ matrix is stored in the computer as the $n \times 1$ column vector $\mathbf{x}$ and a $n \times 1$ position vector $\mathbf{p}$. The $i$ th element of $\mathbf{p}$ contains in packed form, the position of $x_{i}$ in the $\mathrm{Z}$ matrix and also additional information which enables the covariance of $x_{i}$ and $x_{j}$ to be either calculated using the above formula or to be set to zero. (This is the usual case when $x_{i}$ and $x_{j}$ belong to different sets.) An approximation to the special case in which a covariance is present but one of the associated variances is missing may be made by giving the missing variance an arbitrary value with a small non-zero fractional value for the degrees of freedom.

The iteration is continued until $M_{\theta}=\max \frac{\left(\theta_{r}-\theta_{r-1}\right)^{2}}{\operatorname{var} \theta_{r}}$ is less than a prescribed quantity $a^{2}$, the suffices $r, r-1$ referring to the cycle of iteration and the output then comprises $\mathbf{M}_{\theta}$, the total (weighted) sum of squares, the fitted sum of squares, the estimated expected values, $\mathrm{X}$, of the variances and covariances, $x$, the estimated components, $\theta$, and the variance matrix of $\theta$. The difference between the total and fitted sum of squares gives a $\chi^{2}$ for goodness of fit.

The principle of the test for the effects of linkage is the same as in the unweighted analysis, but the actual application is a little different because in the construction of Mather's (1949) matrices no allowance was made, in formulating the expectation of $V_{153}$, for the small items representing the genetic sampling variation which must be shown by mean values of finite families. This term reflects the genetic variation within families and is therefore related to $V_{253}$. Neglecting it, as Mather did in the interests of simplicity, allows the effect of linkage to be accommodated by omitting $\mathrm{V}_{2 \mathrm{S3}}$ from the analysis, but its inclusion brings the second rank components $D_{2}$ and $\mathrm{H}_{2}$ into the expectation for $\mathrm{V}_{1 \mathrm{~s} 3}$ which otherwise depends solely 
on the first rank components $D_{1}$ and $H_{1}$, together of course with $E_{2}$. This term for genetic sampling variation was included in the weighted analysis, so that the linkage effects cannot be accommodated by the simple exclusion of $\mathrm{V}_{2 \mathrm{s3}}$. Rather $\mathrm{V}_{2 \mathrm{~s} 3}$ must be retained and a quantity $\mathrm{G}=\frac{1}{4} \mathrm{D}_{2}+\frac{3}{16} \mathrm{H}_{2}$ must be estimated alongside $\mathrm{D}_{1}, \mathrm{H}_{1}$, $\mathrm{E}_{1}$ and $\mathrm{E}_{2}$, this quantity appearing in $\mathrm{V}_{2 s 3}$ and, by virtue of the sampling term, also in $\mathrm{V}_{1 \mathrm{s3}} . \mathrm{D}_{2}$ and $\mathrm{H}_{2}$ appear in the same combinations in both statistics so that this inclusion requires and indeed permits the estimation of only the single additional component $\mathrm{G}$ as defined above. The difference between the two residual $\chi^{2}$, one from the analysis when $\mathrm{D}$ and $\mathrm{H}$ are assumed to be homogeneous (i.e. when no allowance is made for linkage, comparable with the inclusive unweighted analysis) and the other from the analysis where $G$ is introduced (i.e. where allowance is made for linkage effects comparable with the exclusive analysis) provides a $\chi^{2}$ testing for linkage effects in essentially the same way as the linkage mean square does in the unweighted analysis. The only difference is that it provides a test of significance in its own right without any comparison with the residual variation unless of course the $\chi^{2}$ reflecting this residual variation is itself significant. In fact from table 8 (a) we obtain by summing the residual $\chi^{2}$ from the four exclusive analyses a value of 7.449 with 8 d.f., which agrees very well with expectation.

The weighted analysis also differed from the unweighted in the present case in one final respect. In the unweighted analysis, no account was taken of the variance between the mean of $F_{2}$ cultures, the variance of $F_{2}$ being found solely from differences among individuals within cultures. In the weighted analysis $\mathrm{V}_{1 \mathrm{~F} 2}$, found as the variance within $F_{2}$ cultures and having the expectation $\frac{1}{2} \mathrm{D}+\frac{1}{4} \mathrm{H}+\mathrm{E}_{1}$, was used exactly as in the unweighted, but an additional statistic was introduced, found as the variance between the means of $\mathrm{F}_{2}$ cultures, these means being based on 10 flies and having the expectation $\frac{1}{20} \mathrm{D}+\frac{1}{40} \mathrm{H}+\mathrm{E}_{2}$. The number of components estimated in the weighted analysis was thus the same as in the unweighted, but the number of statistics used in providing the estimates was raised from six to seven, so that there is one extra degree of freedom for residual variation in the weighted as compared with the unweighted treatment. The inclusive weighted analysis provides therefore a $\chi^{2}$ for 3 degrees of freedom for residual variation and in the equivalent of the exclusive analysis, one for 2 degrees of freedom, their difference being a $\chi^{2}$ testing linkage and having one degree of freedom just as the linkage mean square had one degree of freedom in the unweighted treatment.

The results of that test for the effects of linkage can be seen from the bottom lines of table 8 (a) where are set out the final values of $\chi^{2}$ from the inclusive and exclusive analyses of the four parts of the experiment. The linkage $\chi_{[1]}^{2}$ is significant $(P=$ just over 0.02$)$ in the $\mathrm{B} \times \mathrm{S}$ males, but not significant in any of the other three, the $\chi^{2}$ being indeed rather small for the $\mathrm{S} \times \mathrm{B}$ females. If, however, we 
add all four linkage $\chi^{2}$ together to find $\chi_{[4]}^{2}=9.595$ the joint evidence again appears to be strongly suggestive of linkage effects since $\mathbf{P}$ is only just over 0.02 . As with the unweighted analysis, however, the evidence is not as good as might seem at first sight since if we take

TABLE 8

The effect of iteration on:

(a) The values of $x^{2}$

\begin{tabular}{|c|c|c|c|c|c|c|}
\hline & \multicolumn{3}{|c|}{ BS $\sigma^{*}$} & \multicolumn{3}{|c|}{ SB $ð$} \\
\hline & $\begin{array}{l}\text { Inclusive } \\
(3 \mathrm{df})\end{array}$ & $\begin{array}{l}\text { Exclusive } \\
\quad(2 \mathrm{df})\end{array}$ & $\begin{array}{l}\text { Linkage } \\
\text { (I df) }\end{array}$ & $\begin{array}{l}\text { Inclusive } \\
\text { ( } 3 \mathrm{df})\end{array}$ & $\begin{array}{l}\text { Exclusive } \\
\quad(2 \mathrm{df})\end{array}$ & $\begin{array}{l}\text { Linkage } \\
\text { (I df) }\end{array}$ \\
\hline $\begin{array}{l}\text { After I cycle } \\
\text { After } 2 \text { cycles } \\
\text { Final value }\end{array}$ & $\begin{array}{l}6 \cdot 502 \\
9 \cdot 44^{8} \\
9 \cdot 276\end{array}$ & $\begin{array}{l}3 \cdot 585 \\
4 \cdot 306 \\
4 \cdot 105\end{array}$ & $\begin{array}{l}2 \cdot 917 \\
5 \cdot 142 \\
5 \cdot 171\end{array}$ & $\begin{array}{l}I \cdot 282 \\
I \cdot 458 \\
I \cdot 454\end{array}$ & $\begin{array}{l}0 \cdot 101 \\
0 \cdot 102 \\
0 \cdot 102\end{array}$ & $\begin{array}{l}I \cdot I 8 I \\
I \cdot 35^{6} \\
I \cdot 35^{2}\end{array}$ \\
\hline & \multicolumn{3}{|c|}{ BS 우 } & \multicolumn{3}{|c|}{$\mathrm{SB}$ ㅇ } \\
\hline $\begin{array}{l}\text { After I cycle } \\
\text { After } 2 \text { cycles } \\
\text { Final value }\end{array}$ & $\begin{array}{l}4.413 \\
3.685 \\
3 \cdot 638\end{array}$ & $\begin{array}{l}0.750 \\
0.592 \\
0.582\end{array}$ & $\begin{array}{l}3 \cdot 663 \\
3 \cdot 093 \\
3 \cdot 056\end{array}$ & $\begin{array}{l}2 \cdot 738 \\
2 \cdot 733 \\
2 \cdot 676\end{array}$ & $\begin{array}{l}2 \cdot 632 \\
2 \cdot 725 \\
2 \cdot 660\end{array}$ & $\begin{array}{l}0 \cdot 106 \\
0.008 \\
0.016\end{array}$ \\
\hline
\end{tabular}

(b) The estimates, as measured by $\sqrt{M_{\theta}}$

\begin{tabular}{|c|c|c|c|c|}
\hline & \multicolumn{2}{|c|}{ BS $\pi$} & \multicolumn{2}{|c|}{ SB 6} \\
\hline & Inclusive & Exclusive & Inclusive & Exclusive \\
\hline \multirow[t]{2}{*}{$\begin{array}{l}\text { After I cycle } \\
\text { After } 2 \text { cycles }\end{array}$} & $\begin{array}{l}0.122 \\
0.008\end{array}$ & $\begin{array}{l}0.447 \\
0.097\end{array}$ & $\begin{array}{l}0.025 \\
0.000\end{array}$ & $\begin{array}{l}0.008 \\
0.000\end{array}$ \\
\hline & \multicolumn{2}{|c|}{$\mathrm{BS} \stackrel{+}{+}$} & \multicolumn{2}{|c|}{ SB $q$} \\
\hline $\begin{array}{l}\text { After I cycle } \\
\text { After } 2 \text { cycles }\end{array}$ & $\begin{array}{l}0 \cdot 13^{8} \\
0 \cdot 006\end{array}$ & $\begin{array}{l}0.099 \\
0.003\end{array}$ & $\begin{array}{l}0.235 \\
0.032\end{array}$ & $\begin{array}{l}0.149 \\
0.015\end{array}$ \\
\hline
\end{tabular}

This table shows the maxinum change in an estimate in the next cycle, relative to its standard error. Thus the entry 0.122 implies that the difference between the 1 st and 2 nd cycle estimates is at most 0.122 of its standard error.

the $\chi_{[1]}^{2}$ for linkage from the pooled data, comparable with the overall linkage test in the unweighted analysis (table 6), we find it to be only 0.7189 . This implies that the individual groups of data must be heterogeneous in the evidence they provide for linkage. It should, however, be realised that in any case the evidence for linkage in biometrical genetics is not to be judged in the same way as that from the linkage experiments of classical genetics, because very loose or very tight linkage will have little effect in changing the statistics by which variation is measured in biometrical analyses. In other words, the failure to detect an effect of linkage biometrically does not imply 
that linkage and recombination in the classical sense are effectively inoperative in the system: it merely implies that the change recombination produces from generation to generation in the components of variation is not large, even where its ultimate consequences for, for example, progress under selection may be far from negligible.

The final values yielded by the weighted analysis for the components of variation are set out in table 9. The figures shown are those from the inclusive analysis and they may therefore be regarded as invalidated in the strict sense by the evidence for linkage effects. They are nevertheless taken so as to facilitate comparisons with the results of the unweighted analysis where the inclusive results are used. In any case, the differences between the estimates of $\mathrm{D}$ and $\mathrm{H}$ from the inclusive weighted analysis are hardly likely to differ materially from the values yielded for $D_{1}$ and $H_{1}$ by the exclusive operation.

TABLE 9

Estimates of the components of variation from the weighted inclusive analysis

\begin{tabular}{|c|c|c|c|c|c|}
\hline & BS $\sigma^{*}$ & BS $q$ & SB d & SB 우 & $\begin{array}{c}\text { Averaged } \\
\text { overall }\end{array}$ \\
\hline $\begin{array}{l}\mathrm{D} \\
\mathrm{H} \\
\mathrm{E}_{1} \\
\mathrm{E}_{2}\end{array}$ & $\begin{array}{l}2 \cdot 4882 \pm 0 \cdot 4429 \\
0 \cdot 0944 \pm 1 \cdot 1216 \\
2 \cdot 6954 \pm 0 \cdot 1442 \\
0 \cdot 4277 \pm 0.0616\end{array}$ & $\begin{array}{r}3 \cdot 9784 \pm 0 \cdot 4683 \\
-3 \cdot 8713 \pm 1 \cdot 0596 \\
2 \cdot 5636 \pm 0 \cdot 1338 \\
0.3916 \pm 0 \cdot 0557\end{array}$ & $\begin{array}{l}2 \cdot 3083 \pm 0.4423 \\
2 \cdot 8432 \pm 1 \cdot 0489 \\
2 \cdot 2314 \pm 0 \cdot 1237 \\
0.3359 \pm 0.0520\end{array}$ & $\begin{array}{l}2 \cdot 7499 \pm 0.4573 \\
2.5477 \pm 0.9983 \\
1.9525 \pm 0.1104 \\
0.3166 \pm 0.0493\end{array}$ & $\begin{array}{l}2.8970=0.2269 \\
0.3783 \pm 0.5300 \\
2 \cdot 3617 \pm 0.0648 \\
0.3695 \pm 0.0283\end{array}$ \\
\hline
\end{tabular}

Comparing the weighted estimates of the components with the unweighted, the most striking feature is the close similarity of the two sets of estimates. The weighted estimates of $\mathrm{D}$ and $\mathrm{H}$ are, however, on the whole smaller than the unweighted, the difference being more noticeable for $\mathrm{H}$ than for $\mathrm{D}$. Even so, no comparable figures differ by amounts even approaching significance and the very same unexpectedly high value for $\mathrm{D}$ and negative value for $\mathrm{H}$ are obtained for $\mathrm{B} \times \mathrm{S}$ females, with this difference, that the value of $\mathrm{H}$ is now significantly negative. Since by definition, $\mathrm{H}$ is a quadratic quantity, a negative value is nonsensical and once again the aberrant nature of the results from this part of the experiment is emphasised, but this time even more strongly because of the greater precision of the weighted analysis. This finding also serves further to emphasise the obvious point, if further emphasis be needed, that no refinement of statistical procedure can bring sense out of data which are suspect by genetical criteria.

One further matter requires discussion before we leave the weighted analysis. The process of estimation is iterative and while the number of iterations necessary is relatively unimportant when an electronic computer is available, it becomes of serious moment should, for any reason, a weighted analysis be carried out with the aid of no more 
than a desk calculating machine. The $\chi^{2}$ values after the first and second cycles of calculation are shown for comparison with the final values in table $8(\mathrm{a})$ and the values of $\sqrt{\mathrm{M}_{\theta}}$ which give an upper bound for the computational error of the estimates as a fraction of their standard errors, are set out correspondingly in the second part of the same table. The values of both $\chi^{2}$ change very much more between the results of the first and second cycles than between the latter and final values and the value of $\sqrt{\mathbf{M}_{\theta}}$ is quite small after the second cycle. The conclusion, already reached by Hayman ( 1960 ) from a different set of data, would seem clear; that while two cycles of calculation lead to a correct interpretation, a single cycle is unreliable. It is of interest that the $\chi^{2}$ for $\mathrm{B} \times \mathrm{S}$ males actually rises from the first to the second cycle, no doubt because the weights used initially failed to give full emphasis to some differences between the seven statistics from which the estimates are obtained.

The weights used in the first cycle were empirical in that they were derived from the values actually observed for the statistics. The weights in the subsequent cycles were derived from the values expected for the statistics on the basis of the last set of estimates of the components. If therefore a set of weights approximating better to the true ones could be found with which to start the first cycle, a single cycle of the weighted least squares procedure might be sufficient. Possibly weights derived from the results of the simple unweighted analysis might serve for this purpose and if that were so, the unweighted analysis, followed by a single cycle of the weighted, might well be regarded as a not intolerably heavy task, even where no electronic computer were available. This possibility has not, however, been tested.

\section{THE EFFICIENCY OF UNWEIGHTED ANALYSIS}

The unweighted analysis yielded values for the components of variation which differ from the weighted estimates to only a minor extent. There is thus no reason to suspect that the failure to use weights introduces any material bias into the estimates but one is led to enquire into the relative efficiency of the unweighted method. This may be determined by dividing the sampling variance of the estimates given by the computer by that of the estimate from the unweighted analysis. The variance matrix of the latter set of estimates, $\boldsymbol{\theta}$, is (Nelder, 1960)

$$
\operatorname{var} \theta=\left(\mathbf{a}^{\prime} \mathbf{a}\right)^{-\mathbf{1}} \mathbf{a}^{\prime} \mathbf{v a}\left(\mathbf{a}^{\prime} \mathbf{a}\right)^{-\mathbf{1}}=\mathbf{g}^{\prime} \mathbf{v g}
$$

where the matrix $\mathbf{g}=\mathbf{a}\left(\mathbf{a}^{\prime} \mathbf{a}\right)^{-1}=\mathbf{a c}$ depends only on the generations included in the experiment and is easy to calculate once the inverse $c$-matrix is known.

This procedure gives, of course, the sampling variances expected for the estimates from the unweighted analysis. The standard errors shown in table 7 are, on the other hand, observed errors in that they 
are derived from the differences between the values observed and expected for the statistics in the particular experiment. Measured in this way, these standard errors will themselves be subject to sampling variation which will be large in cases such as the present where errors are derived from a very small number of degrees of freedom. The standard errors of the unweighted estimates actually found in an experiment will thus fluctuate round the values expected from the calculations outlined above.

Reference to tables 7 and ro for the Drosophila results, and to table 12 for others from an experiment with Nicotiana, shows this to be the case in the sense that the unweighted standard errors do not bear to the weighted the relation that the comparative efficiencies

TABLE 10

Comparative efficiencies of the unweighted estimates of the components from the four parts of the unweighted inclusive analysis

\begin{tabular}{|c|c|c|c|c|}
\hline & BS $\sigma^{*}$ & BS $\%$ & SB $\sigma^{*}$ & SB $\%$ \\
\cline { 2 - 4 } & $93 \cdot 8$ & $98 \cdot \mathrm{I}$ & $94 \cdot 0$ & $96 \cdot 3$ \\
$\mathrm{D}$ & $96 \cdot 0$ & $71 \cdot 5$ & $76 \cdot 6$ & $74 \cdot 6$ \\
$\mathrm{H}$ & $8 \mathrm{I} \cdot 3$ & $77 \cdot 5$ & $85 \cdot 9$ & $88 \cdot 5$ \\
$\mathrm{E}_{1}$ & $7 \mathrm{I} \cdot 4$ & $7 \mathrm{I} \cdot 4$ & $59 \cdot 5$ & $57 \cdot \mathrm{I}$ \\
$\mathrm{E}_{2}$ & & & \\
\hline
\end{tabular}

would suggest; sometimes they are larger and sometimes smaller than would be expected on the basis of the measures of relative efficiency which, as we have observed, were calculated from the sampling variation expected for the unweighted estimates obtained from an experiment of this kind. Such expected sampling variances must obviously be used in assessing the relative efficiencies for the purpose of planning future experiments. They are general properties of the type of experiment and therefore applicable to all experiments of the kind in question, whereas the relative efficiencies actually observed in any given experiment necessarily reflect its own special circumstances and are therefore applicable to it alone.

Applying this method to the four parts of the experiment gives the percentage efficiencies set out in table ro for the components of variation in the unweighted analysis. For the two genetical parameters $D$ and $H$ and for $E_{1}$, the efficiency is never less than 75 per cent. and indeed for $\mathrm{D}$ the unweighted analysis sacrifices only about one part in fourteen of the information that the weighted treatment can extract. Even for $E_{2}$, which is of lesser interest than the genetical parameters, well under half the information is lost.

The relative efficiencies will depend on the structure of the experiment, that is on the generations included in it, on the statistics it yields, and on the relative number of individuals and families from which the various statistics are calculated. It is therefore of interest 
to look at a further experiment of the same general kind as that with Drosophila but which is smaller and shows a somewhat different balance of structure. Data are available for flowering time and plant height in Nicotiana rustica.

The statistics available for both characters in this plant are the same as with Drosophila. Table I I shows the number of degrees of

TABLE II

Degrees of freedom for the statistics in the Nicotiana experiment and the balances of the Nicotiana and Drosophila experiments

\begin{tabular}{|c|c|c|c|}
\hline \multirow{2}{*}{ Statistic } & \multicolumn{2}{|c|}{ Nicotiana } & \multirow{2}{*}{$\begin{array}{l}\text { Drosophila } \\
\text { Balance }\end{array}$} \\
\hline & $\begin{array}{l}\text { Degrees of } \\
\text { freedom }\end{array}$ & Balance & \\
\hline $\begin{array}{l}V_{1 F_{2}} \\
V_{1 F_{3}} \\
W_{1 S_{23}} \\
V_{2 S_{3}} \\
E_{1} \\
E_{2}\end{array}$ & $\begin{array}{r}80 \\
24 \\
24 \\
200 \\
200 \\
42\end{array}$ & $\begin{array}{r}40 \\
12 \\
12 \\
100 \\
100 \\
21\end{array}$ & $\begin{array}{r}\text { IO } \\
\text { I I } \\
\text { I I } \\
\text { I OO } \\
\text { I } 6 \\
2\end{array}$ \\
\hline
\end{tabular}

freedom on which each statistic is based. An attempt has also been made in this table, to illustrate and compare the relative balances of the two experiments by showing the number of degrees of freedom for each statistic expressed relative to the number for $V_{2 \mathrm{~s} 3}$ taken as I0o. Thus in Nicotiana, $\mathrm{V}_{2 \mathrm{~s} 3}$ is based on 200 degrees of freedom and

TABLE 12

Components of variation and efficiency of unweighted estimates in Nicotiana

\begin{tabular}{|c|c|c|c|c|c|c|}
\hline & \multicolumn{2}{|c|}{ Flowering time components } & \multirow{2}{*}{$\begin{array}{l}\text { Relative } \\
\text { efficiency }\end{array}$} & \multicolumn{2}{|c|}{ Plant height components } & \multirow{2}{*}{$\begin{array}{l}\text { Relative } \\
\text { efficiency }\end{array}$} \\
\hline & Unweighted & Weighted & & Unweighted & Weighted & \\
\hline $\begin{array}{l}\mathrm{D} \\
\mathrm{H} \\
\mathrm{E}_{1} \\
\mathrm{E}_{2}\end{array}$ & $\begin{array}{c}6 \cdot 5 \mathrm{I} \pm 12 \cdot 63 \\
30 \cdot 50 \pm 31 \cdot 22 \\
4 \cdot 9 \mathrm{I} \pm 3 \cdot 49 \\
2 \cdot 44 \pm 2 \cdot 73\end{array}$ & $\begin{array}{c}3.21 \pm 7.30 \\
43.72 \pm 13.56 \\
4.56 \pm 0.45 \\
1.52 \pm 0.32\end{array}$ & $\begin{array}{l}95 \\
79 \\
60 \\
\text { I I }\end{array}$ & $\begin{array}{l}19.45 \pm 6 \cdot 95 \\
10.98 \pm 17 \cdot 18 \\
7.48 \pm 1 \cdot 91 \\
5.4^{8} \pm 1 \cdot 50\end{array}$ & $\begin{array}{c}20 \cdot 54 \pm 11 \cdot 7 \mathrm{I} \\
9 \cdot 28 \pm 19 \cdot 36 \\
7 \cdot 26 \pm 0 \cdot 72 \\
6 \cdot 20 \pm \mathrm{I} \cdot 26\end{array}$ & $\begin{array}{l}86 \\
66 \\
71 \\
55\end{array}$ \\
\hline
\end{tabular}

$\mathrm{V}_{1 F 2}$ on 80 so that when $\mathrm{V}_{2 \mathrm{~S} 3}$ takes Ioo on the relative scale, $\mathrm{V}_{1 \mathrm{F2}}$ takes 40. The chief differences between the experiments lie in the greater relative weight of $\mathrm{V}_{1 \mathrm{~F} 2}, \mathrm{E}_{1}$ and $\mathrm{E}_{2}$ in $\mathcal{N}$ icotiana.

There was no evidence of linkage exerting an effect in respect of either character and the estimates given are therefore taken from the inclusive evaluation. The weighted and unweighted estimates of the components of variation are shown for both characters of Nicotiana in table 12 together with their standard errors and the relative 
efficiencies of the unweighted estimates. As in Drosophila, the unweighted estimates are encouragingly similar to the weighted, the greatest relative discrepancy being in the $\mathrm{D}$ of flowering time. Neither this difference, nor any other between the weighted and unweighted estimates, is anywhere near significance. The standard errors of both sets of estimates are large as would be expected from an experiment much smaller in size than that with Drosophila, but even so the weighted analysis clearly establishes the presence of dominance in respect of flowering time which the unweighted analysis fails to do.

The efficiencies of the unweighted estimates relative to the weighted are very much the same for Nicotiana as for Drosophila apart from the case of $E_{2}$ in flowering time. Evidently the difference in balance of the two experiments has had little effect on the efficiency of the unweighted analysis. In an example discussed by Nelder (1960), however, the efficiency of the unweighted method was distinctly lower. This case contrasted with the present examples in that the ratio of the greatest to the smallest weights it involved was IOO : I, whereas in our experiments this ratio always lay between $\mathrm{I} 5: \mathrm{I}$ and $30: \mathrm{I}$. This presumably accounts for the difference in efficiency of the unweighted analyses. It would thus seem that despite its shortcomings, the simple unweighted treatment may be expected to yield reasonable estimates of the components of variation, though the values found for their standard errors cannot be regarded as fully reliable.

\section{SUMMARY}

Two inbred lines, Oregon (B) and Samarkand (S) of Drosophila melanogaster were crossed reciprocally. In addition to the $\mathrm{F}_{1}$ 's and $\mathrm{F}_{2}$ 's, biparental progenies of the third generation (BIPS) were raised from both crosses. The number of sternopleural chaetæ were counted in all these generations and the components of variation $\left(D, H, E_{1}\right.$ and $\mathrm{E}_{2}$ ) in respect of this character were estimated using the method devised by Mather (1949). Estimates were obtained in quadruplicate by using data from males and females separately in the two halves of the experiment stemming from the reciprocal crosses. The results from the $\mathrm{B} \times \mathrm{S}$ females proved to be aberrant for reasons which are not known. The analyses yielded no clear indication of the presence of linkage on the variation in respect of this character.

This unweighted method of analysis is easy to use but makes no allowance for the differences in the precision of the statistics for the various generations or for correlations among these statistics. A weighted method which accommodates these differences in precision and correlation has been described by Nelder (I 960 ) and this was applied to the results, the iterative calculations being carried out on the Rothamsted electronic computer. Two cycles of iteration would appear generally to be adequate in using this method.

The simple unweighted analysis yields estimates of the components 
of variation which do not differ significantly from those resulting from the weighted analysis. The relative efficiency of the unweighted analysis varies from 60 to over 90 per cent. for the various components of variation over the four parts of the experiment.

A further set of data for flowering time and plant height in Nicotiana rustica were similarly analysed by both methods. Though the broad structure of the experiment was similar to that of the one with Drosophila the relative precisions of the statistics it yielded were somewhat different. The unweighted estimates of the components stood in very much the same relation to the weighted estimates as in Drosophila and the efficiency of the weighted method was also much the same.

\section{REFERENCES}

CAVALli, L. L. I952. An analysis of linkage in quantitative inheritance. Quantitative Inheritance. Ed. E. G. R. Reeve and C. H. Waddington. H.M.S.O. London, I35-1 44 .

FAI,CONER, D. S. I96o. Introduction to Quantitative Genetics. Oliver and Boyd, London.

HAYMAN, B. I. 1960. Maximum likelihood estimation of genetic components of variation. Biometrics, $16,369-38 \mathrm{I}$.

HAYMAN, B. I., AND MATHER, K. 1955. The description of genic interactions in continuous variation. Biometrics, $I I, 69-82$.

kempthorne, o. 1957. An Introduction to Genetic Statistics. John Wiley and Sons, New York.

Lerner, I. M. 1950. Population Genetics and Animal Improvement. Cambridge University Press.

Mather, K. I949. Biometrical Genetics. Methuen, London.

MATHER, K., AND JONES, R. MORLEY. 1958. Interaction of genotype and environment in continuous variation. I. Description. Biometrics, 14, 343-349.

MATHER, K., AND VINES, A. 1952. The inheritance of height and flowering time in a cross of Nicotiana rustica. Quantitative Inheritance. H.M.S.O. London, 49-79.

NELDER, J. A. 1953. Statistical models in biometrical genetics. Heredity, 7, I I I-I 9.

NELDER, J. A. 196o. The estimation of variance components in certain types of experiment on quantitative genetics. Biometrical Genetics. Ed. O. Kempthorne. Pergamon Press, 139-158.

OPSAHL, B. 1956. The discrimination of interactions and linkage in continuous variation. Biometrics, $12,415-432$. 